\title{
Thai Women Role for Promoting Public Health in Northeastern Region of Thailand
}

\author{
Wichid Pumchan \\ Regional Development Strategies Program \\ Surindra Rajabhat University \\ Email: theppum@gmail.com
}

\section{Doi:10.5901/mjss.2013.v4n3p457}

\section{Abstract}

The research was qualitative approaches. The research design for qualitative research was In-Dept Interview with Ethnographic research technique of 10 Thai women who live at Mekong River bank in Ubon Ratchani Province, the Northeastern region of Thailand. The content from qualitative research was analyzed to construct the questionnaire for quantitative research. Factor analysis was used for determination the component factors. The objectives of this research were 1) to study Thai woman role related to promote public health in Northeastern region of Thailand and 2) to analyze content of Thai woman role to construct items for factor analysis to identify the component of Thai woman role related to promote public health in Northeastern region of Thailand. There were 6 components were constructed from 60 items. The 6 components were Thai woman role in self-health care, Thai woman role in household health promotion Thai woman role in community health promotion, woman role in public health promotion for woman and child, woman role in public health promotion for elderly people, and woman role in public health prevention for risk behaviour.

Keywords: Thai Women Role, Promoting, Public Health, Northeastern Region, Thailand

\section{Introduction}

The ancient social status of human being over the world had divided role, function and responsibility of family member clearly. The historical evidences through drawing on cave wall and sculpture, it is evidently seen that the gender role identifies duty scope because male is strong sex so he must go to hunt and build the shelter and female is weaker sex, therefore she has duty of cooking and housekeeping. Therefore this makes different pattern way of life for both sexes in role dimension. However, at present social situation is changed and adjusted in accordance with social current, therefore the role of woman and man are changing with more modern and equality that defines by society. This effects to adjusting way of life from prior. It is obviously seen for woman role in present society has tendency to increase her capability by entering to economic, social and politic activities.

Woman role is a social mechanism that globalization age pays attention and awareness to the woman competency by considering it as part of social support from women working in different aspects such as public health promotion. It has been developed a small group in community by building network to connect at social region level to national level. Therefore, it has been accepted from different governmental sectors such as Red Cross unit that has role in public health with taking numerous burdens for people suffer. A variety of women roles bring the women to gather for doing some activity that needs to use the women roles with full ability to support and promote in public health effectively (Phanurat, 2009). Particularly, women gathering as charity organization or public benefit organization, in Thailand it is named as Non Government Organizations (NGOs) that is founded in Thai society for long time ago. These organizations have prominence and unique that come together social development under content with direct influence towards public benefit organization in aspect of activity occurrence and working process. However, they are different in accordance with age and time and they can be classified into 9 groups (Pukdeebutra and Khemmaratana, 2000). It was classified in accordance with the relationship with government, role of organization, duty, purpose, Dr. Ampol watanachinda, survey $f$ Office of national statisticsm activity, he International Classification of Nonprofit Organizations (ICNPO), and European Foundation Center (EFC). Nevertheless public benefit organization as only women gathering with aim to function on public health is subjective and clear in the initiated age or pioneer age until present. There are few prominent organization that are obviously seen by society until present is The Thai Red Cross Council (Settapongkul, 2000). This organization has continuous development and has network in provincial level that is called Provincial Red Cross Chapter. 
In the past, woman role in public health promotion had power and high competency with gentle and delicate of being as feminine because she is close to her children since baby to be adult. She helps and protects her children to save from sickness based on her love and closely care with power of mother. She teaches and trains her children to be strong body, mind and society to be able to self-dependence in terms of sanitation. Moreover she has very strong power to look after other health in family naturally such as cooking health food and preparing medicine and arranging house to be clean and save with correct hygiene and taking care for cleaning cloth for family members. Moreover, in community women have roles of public health promotion. It is obviously seen in Thailand that they are public health volunteer for village across the country and they are majority of Village Health Volunteer (VHV). VHV is accepted as volunteer of health personnel that is a very important leader for village health promotion because VHV is driving agent for fundamental health in community in accordance with World Health Organization (WHO) guidelines of 14 components (Nontasoot, 1994). These guidelines are believed that they will support the community to be self-dependence in health aspect and be strong community for good living. The importance is that VHV who practices this work has majority as women since practice of public health volunteer is a voluntary activity that they must devote time and mind power for public based on women psychology of women willing and accepting to do for public than men (Lhopetch, 2011).

Moreover, it should be considered on cultural ecology is the study of human adaptations to social and physical environments. Human adaptation refers to both biological and cultural processes that enable a population to survive and reproduce within a given or changing environment (Barnett, 1950). This may be carried out diachronically (examining entities that existed in different epochs), or synchronically (examining a present system and its components). The central argument is that the natural environment, in small scale or subsistence societies dependent in part upon it, is a major contributor to social organization and other human institutions (Wikipedia, 2013).

In the first decade of the 21st century, the explanation about humans can develop a more acceptable cultural relationship with the environment. An example is sacred ecology, a sub-topic of cultural ecology, produced by Fikret Berkes in 1999. It seeks lessons from traditional ways of life in Northern Canada to shape a new environmental perception for urban dwellers. This particular conceptualization of people and environment comes from various cultural levels of local knowledge about species and place, resource management systems using local experience, social institutions with their rules and codes of behaviour, and a world view through religion, ethics and broadly defined belief systems (Berkes, 1999; Wikipedia, 2013). However, it might be concluded that culture is a balancing act between the mindset devoted to the exploitation of natural resources and that, which conserves them. Perhaps the best model of cultural ecology in this context is, inconsistently, the disparity of culture and ecology that have occurred when Europeans suppressed the age-old native methods of land use and have tried to settle European farming cultures on soils noticeably unable of supporting them. There is a sacred ecology associated with environmental awareness, and the job of cultural ecology is to inspire urban residents to develop a more acceptable sustainable cultural relationship with the environment that supports them, therefore if there is no human, there is no culture as well as there is no culture, there is no human (Wikipedia, 2013; Rapeepat, 2008; Clifford, 1973).

Especially in Thailand, the regulation of Ministry of Public Health about village health volunteer B.E.201, defines meaning of $\mathrm{VHV}$ and recruitment process as the followings. VHV refers to a person who was selected from village or community and passed the standard of VHV training course along with the committee definition as 1) health volunteer at village, 2) Bangkok health volunteer in Bangkok boundary, and 3) other health volunteer according to Ministry of Public Health has abbreviation in Thai as "Or Sor Mor" and in English called Village Health Volunteer (VHV). The duties of VHV are as the followings. 1) Perform follows the policy of Ministry of Public Health. 2) Carry out public relation or campaign arrangement of public health and provide basic health knowledge. 3) Provide health service according to regulations of Ministry of Public Health or other regulations. 4) Organize inspection activity and prevent health problem that is fitting to local health status. 5) To be leader as health behavior change to develop community quality of life via community participation and corroborate with supportive plan of local administration and other sources. 6) Provide knowledge in aspect of health right and benefit to reach health service for people and participate to advise opinion of community about public policy of health. 7) Study, self develop and participate to meeting and perform to requirement of other sectors. 8) Implement follows the standard of VHV competency. 9) Corporate health work implementation in community and work together with government officer and local organization administration including other local developmental organization. Generally, VHV is pattern of people participation for self, family and community health cares via training process from officer public health and they practice with public mind. Ministry of Public Health has implemented since 1977. Currently, there are 1 million and one hundred thousand of VHVs and each of them takes responsibility to look after 8-15 households (Ministry of Public Health, 2011). 
However, Thai Women role for promoting public health in this study also concern in aspect not only role, duty, and responsibility according to regulation of Ministry of Public Health but also concern in terms of cultural ecology of Northeastern region of Great Mekong River couture that embedded for hundreds year. There was a study of Wiwatanapatapi, (2006) indicated that the process of women empowerment in Northeastern region revealed that women empowerment involved self-changing, change others, and change the society. It was women power with selfcompetency, ability to persuade others to believe and be accepted to practice together, therefore women will be empowered at different levels according to social condition but it needs women' patience and it depends to the degree of women attempt. Consequently, the real woman leader would be able to make the other to change their behavior (Wiwatanapatapi, 2006).

From reasons and components mentioned above, to study on "Thai Women Role for Promoting Public Health in Northeastern Region of Thailand", it is very interesting and important to understand the Thai women role for promoting public health in public benefit organizations, particularly at the Great Mekong River Basin in Ubon Ratchathani Province. In order to deeply understand Thai Women Role at Mekong River bank in the Northeastern of Thailand, the finding will use to support and promote Thai women role to be stronger and reach full competency in public health effectively and sustainably.

\section{Research Objective}

The objectives of this research were as the followings:

1. To study Thai woman role related to promote public health in Northeastern region of Thailand.

2. To analyze content of Thai woman role to construct items for factor analysis to identify the component of Thai woman role related to promote public health in Northeastern region of Thailand.

\section{Methodology}

1.1 Qualitative research was used for data collection from In-Depth Interview form with 10 Thai women who live at Mekong River bank in Ubon Ratchani Province Red Cross Chapter Committee in Ubon Ratchani Province, the Northeastern region of Thailand.

1.2 The research design for qualitative research was In-Dept Interview with Ethnographic research technique of with 10 Thai women (Chantarawanich, 1997; Thiengkamol, 2011a).

\section{Results}

\subsection{In-Depth Interview}

The results of In-Depth Interviews with 10 Thai women who live at Mekong River bank in Ubon Ratchani Province, the Northeastern region of Thailand. It revealed that there were 6 components were constructed from 60 items. The 6 components were The 6 components were Thai woman role in self-health care, Thai woman role in household health promotion, Thai woman role in community health promotion, Thai woman role in public health promotion for woman and child, Thai woman role in public health promotion for elderly people, and Thai woman role in public health prevention for risk behaviour as illustrated in Table 1, 2, 3, 4, 5, and 6.

\subsubsection{Component 1: Thai woman role in self-health care}

The details of each item obtained from content analysis of In-Dept Interview were presented as the following in table 1.

Table 1. Content Analysis Results of Component 1

\begin{tabular}{|c|l|}
\hline Items & Component 1: Thai woman role in self-health care \\
\hline 1 & Woman practices according to 10 health rules. \\
\hline 2 & Woman brushes her teeth at least two time a day. \\
\hline 3. & Woman takes baht two times a day. \\
\hline 4. & Woman washes her hands before eating. \\
\hline
\end{tabular}




\begin{tabular}{|c|l|}
\hline 5. & Woman washes her hairs at least two times a week. \\
\hline 6. & Woman drinks clean water 8 bottles per day. \\
\hline 7. & Women consumes good nutritional food. \\
\hline 8. & Women consumes well cooked food. \\
\hline 9. & Woman avoids to consume spicy, sweet, salted and sour food. \\
\hline 10. & Woman exercises at least three times a week. \\
\hline 11. & Woman cuts her nails very week. \\
\hline
\end{tabular}

\subsubsection{Component 2: Thai woman role in household health promotion}

The details of each item obtained from content analysis of In-Dept Interview were presented as the following in table 2 .

Table 2. Content Analysis Results of Component 2

\begin{tabular}{|c|l|}
\hline Items & Component 2: Thai woman role in household health promotion \\
\hline 1 & Woman suggests family members to practice according to 10 health rules. \\
\hline 2 & Woman suggests family members to brush their teeth at least two time a day. \\
\hline 3. & Woman suggests family members to take baht two times a day. \\
\hline 4. & Woman suggests family member to wash their hands before eating. \\
\hline 5. & Woman suggests family members to wash their hairs at least two times a week. \\
\hline 6. & Woman suggests family members to drink clean water 8 bottles per day. \\
\hline 7. & Women suggests family members to consume good nutritional food. \\
\hline 8. & Women suggests family members to consume well cooked food. \\
\hline 9. & Woman suggests family members to avoid to consume spicy, sweet, salted and sour food. \\
\hline 10. & Woman suggests family members to exercise at least three times a week. \\
\hline 11. & Woman suggests family members to cut their nails very week. \\
\hline
\end{tabular}

\subsubsection{Component 3: Thai woman role in community health promotion}

The details of each item obtained from content analysis of In-Dept Interview were presented as the following in table 3.

Table 3. Content Analysis Results of Component 3

\begin{tabular}{|l|l|}
\hline Items & Component 3: Thai woman role in community health promotion \\
\hline 1 & Woman suggests community people to exercise at least three times a week. \\
\hline 2 & Woman suggests community people to avoid smoking. \\
\hline 3. & Woman suggests community people to avoid alcohol drinking. \\
\hline 4. & Woman suggests community people to avoid junk food. \\
\hline 5. & Woman suggests community people to consume well cooked food. \\
\hline 6. & Woman suggests community people who have chronic disease to go to see doctor regularly. \\
\hline 7. & Woman suggests community people about primary health care. \\
\hline 8. & Woman suggests community people to avoid drug addict. \\
\hline
\end{tabular}

\subsubsection{Component 4: Thai woman role in public health promotion for woman and child}

The details of each item obtained from content analysis of In-Dept Interview were presented as the following in table 4.

Table 4. Content Analysis Results of Component 4

\begin{tabular}{|c|l|}
\hline Items & Component 4: Thai woman role in public health promotion for woman and child \\
\hline 1 & Woman suggests child to avoid drug addict. \\
\hline 2 & Woman suggests child to avoid smoking. \\
\hline 3. & Woman suggests child to avoid alcohol drinking. \\
\hline 4. & Woman suggests mother to prepare good and clean food for child. \\
\hline 5. & Woman suggests mother to take her child to get vaccine according to the age. community people to avoid drug addict. \\
\hline
\end{tabular}


$6 . \quad$ Woman suggests the primary health care for mother.

7. Woman provides method for infectious disease prevention to mother such as diarrhoea and dengue fever.

8. Woman suggests mother how to take care the child when has fever before go to see doctor.

$9 . \quad$ Woman suggests mother to exercise thrre time a week.

\subsubsection{Component 5: Thai woman role in public health promotion for elderly people,}

The details of each item obtained from content analysis of In-Dept Interview were presented as the following in table 5.

Table 5. Content Analysis Results of Component 5

\begin{tabular}{|c|l|}
\hline Items & Component 5: Thai woman role in public health promotion for elderly people \\
\hline 1 & Woman suggests elderly people for self-health care. \\
\hline 2 & Woman suggests elderly people to have a light exercise. \\
\hline 3. & Woman suggests elderly people to have good temper. \\
\hline 4. & Woman suggests elderly people to move slowly. \\
\hline 5. & Woman suggests elderly people to see doctor regularly. \\
\hline 6. & Woman suggests elderly people to have avoid smoking and alcohol drinking. \\
\hline 7. & Woman suggests elderly people to consume light meal and soft vegetable. \\
\hline 8. & Woman suggests elderly people to do mediation. \\
\hline
\end{tabular}

\subsubsection{Component 6: Thai woman role in public health prevention for risk behaviour}

The details of each item obtained from content analysis of In-Dept Interview were presented as the following in table 6.

Table 6. Content Analysis Results of Component 6

\begin{tabular}{|c|l|}
\hline Items & Component 6: Thai woman role in public health prevention for risk behaviour \\
\hline 1 & Woman distributes her knowledge of exercise for people at least three time a week. \\
\hline 2 & Woman distributes her knowledge of clean food good taste campaign. \\
\hline 3. & Woman distributes her knowledge on stop eating uncooked food. \\
\hline 4. & Women distributes her knowledge on cancer risk due to consume roasted meat. \\
\hline 5. & Woman distributes her knowledge on disease risk of junk food to avoid obesity. \\
\hline 6. & Woman give her knowledge about smoking harmfulness to avoid cancer. \\
\hline 7. & Woman distributes her knowledge of good nutritional food to have good health. \\
\hline 8. & Woman distributes her knowledge for avoiding too sweet, spicy and sour food. \\
\hline 9. & Woman distributes her knowledge on alcohol drinking that risk for accident. \\
\hline 10. & Women distributes her knowledge on dangerous of drug addict. \\
\hline 11. & Women distributes her knowledge on sex risk. \\
\hline 12. & $\begin{array}{l}\text { Woman distributes her knowledge on risk factors of smoking for many chronic diseases, } \\
\text { including cancer, lung diseases, and cardiovascular diseases }\end{array}$ \\
\hline 13. & Women distributes her knowledge to people to avoid the high energy food. \\
\hline
\end{tabular}

\section{Discussion}

It might be concluded that this study indicates that the women play very significant role for promoting self-health care and public health whether in her family, community and society including individual level and all age groups. Particularly, the woman who works for public like as VHV, she must have high public consciousness to serve not only her family but also for community and society. Even tough, VHV receives 800 baths per month from the government but this amount of money cannot compensate for her voluntary mind that devotes time and her power to do for public health. Therefore, most of VHV of Thailand are women because she has a spirit of mother together with the Asian culture and tradition, women take responsible not only in family and her career as well. Moreover, her responsible for promoting public health in various aspects as Thai woman role in self-health care, Thai woman role in household health promotion, Thai woman role in community health promotion, Thai woman role in public health promotion for woman and child, Thai woman role in public health promotion for elderly people, and Thai woman role in public health prevention for risk behaviour will 
empower herself and increase her competency. This will bring outcome of good life quality for everyone and lead to achieve real sustainable development and peaceful society through her mercy and kindness.

\section{Reference}

Barnett, A. 1950 The Human Species: London: MacGibbon and Kee.

Berkes, F. 1999 Sacred ecology: traditional ecological knowledge and resource management. Taylor and Francis.

Chantarawanich, S. (1997). Qualitative Research. Bangkok: Chulalongkorn University Press.

Wiwattanapatapi, K. (2008). The Establishment Process of Women's Leadership in Isan Culture.

Lhopetch, S. (2011). Associated Factors to Role Performance in Primary Health Care of Village Health VolunteersJournal of Yala Rajabhat University. Vol.6 No.2 July - December 2011.

Ministry of Public Health. (2011). Regulations of Ministry of Public Health: Village Health Volunteer, B.E. 2554. Nonthaburi: Ministry of Public Health, Thailand.

National Economic and Social Development Board Office of the Prime Minister. (2013). The Eleventh National Economic and Social Development Plan (2012-2016). Retrieved from: http://www.nesdb.go.th/Portals/0/news/plan/p11/Plan11_eng.pdf

Nontasoot, A. (1994). Concepts, Principles, and Implementation of Fundamental Public Health.Bangkok: Office of Commission of Primary Health Care.

Pukdeebutra, J. and Khemmaratana, P. (2000). Type of Public Benefit Organization. Bangkok: National Institute of Development Administration

Phanurat, A. (2009). Teaching material for Subject of Local Study. Surin: Surindra Rajabhat University.

Rapeepat, A. (2008). Culture is Meaning: Theory and Method of Clifford Geertz. Bangkok: Princess Maha Chakri Sirindhorn Anthropology Centre (Public Enterprise).

Settapongkul, S. (2000).Women Development Organization and Value Change in Women and Men Roles that impacted to Women Right and Welfare. Bangkok: TPN Press.

Thiengkamol, N. (2011a). Holistically Integrative Research. 2nd Edition. Bangkok: Chulalongkorn University Press.

Wikipedia. (2013). Cultural Ecology. Retrieved from: http://en.wikipedia.org/wiki/Cultural_ecology 